\title{
EPISTOLARIO
}

\section{Margarita XIRGU / Manuel AZNAR SOLER y Francesc FOGUET I BOREU (eds.)}

\author{
(Sevilla: Renacimiento, 2019, 556 págs.)
}

El presente volumen recoge la correspondencia completa de Margarita Xirgu. Se trata de un documento excepcional que ofrece información sobre la vida cotidiana, la manera de pensar y las vicisitudes emocionales de un auténtico mito teatral del exilio republicano. Dos investigadores de primerísimo nivel, Manuel Aznar Soler - especialista en literatura y teatro del exilio republicano, director de fructíferos proyectos de investigación y autor de incontables estudios sobre figuras tan señeras como Max Aub, Valle-Inclán, Rivas Cherif o María Casares - y Francesc Foguet i Boreu -investigador de trayectoria prolífica, y autor, entre otros muchos estudios, de Margarida Xirgu. Una vocació indomable (2002) y El teatro catalán en el exilio republicano de 1939 (2016) - se han ocupado de la edición de este material ingente, así como del riguroso estudio introductorio. El epistolario contribuye de manera decisiva a la ampliación y enriquecimiento de nuestra memoria escénica y literaria, sumándose a una valiosa colección de trabajos sobre la tradición teatral republicana, ese "repertorio exiliado" que el franquismo quiso y no pudo borrar del mapa.

Nacida en Molins de Rei en 1988 y fallecida en 1969 en Montevideo, Margarita Xirgu debutó en 1906 como actriz a las órdenes de Rafael Moragas y Juli Vallmitjana. Su presentación pública fue en el Romea, como dama joven en Mar i cel, y poco después estrenaría obras de Santiago Rusiñol, Ignasi Iglésias o Narcís Oller. La etapa catalana de Xirgu, prolijamente documentada en distintos libros de Foguet, se cerró pronto, en 1913; la actriz pasaría después a integrarse a los cenáculos intelectuales de Madrid, donde intentó incluir en su repertorio a algunos de los mejores dramaturgos del momento. Cipriano de Rivas Cherif fue el asesor literario y artístico de la compañía en el Teatro Español, donde, 
entre otras piezas, Xirgu estrenó La corona (1931) de Manuel Azaña, presidente de la Segunda República; Divinas palabras (1933), de Ramón María del Valle-Inclán, que había sido prohibido por la dictadura de Primo de Rivera; y Yerma (1934), de Federico García Lorca. Durante el llamado "bienio negro", la compañía fue expulsada del Español, y el 31 de enero de 1936 la actriz se embarcó para una gira americana de la que jamás regresaría. La dureza de la prensa española hizo que desistiera de volver y postergara su retorno sine die.

Se publica aquí la totalidad de su correspondencia localizada hasta la fecha, las cartas, telegramas y tarjetas postales escritas a lo largo de sesenta años (1909-1969) a su familia y amistades, así como a diversas personalidades de la escena y la cultura españolas del siglo XX. En sus misivas, abundan las notas de dirección y referencias a próximos estrenos, así como a sus filias y fobias escénicas. Queda patente la admiración artística de la actriz - "mediadora espiritual entre los autores y el público" (pág. 129) - por Jacinto Benavente, Eduardo Marquina o los hermanos Álvarez Quintero, así como su amistad durante la dictadura primorriverista con el autor monárquico Joaquín Montaner.

El epistolario se estructura en siete períodos. El primero abarca desde 1909 - inicios artísticos de Margarita Xirgu en la escena catalanahasta 1923. Desde 1914, fecha en que la actriz se integra en la escena madrileña, se impone el castellano como lengua de escritura. Surge ya en estos primeros intercambios el tema recurrente de las servidumbres del teatro comercial y el gusto "estragado y pervertido" del público, al que Xirgu califica de auténtico tirano (pág. 85).

El segundo bloque del epistolario llega hasta 1931, en un momento inmediatamente anterior a la proclamación de la Segunda República. Las cartas van dirigidas, en su mayoría, a Joaquín Montaner, y constituyen un material de gran interés para una historia de la escena española. Se menciona en ellas a actores como Enrique Borrás, Lola Membrives; críticos como Enrique Díez-Canedo, Francisco Madrid, Francisco Pérez de Ayala; empresarios como el marqués de Fontalba y Gregorio Martínez Sierra; directores como Adrià Gual y Cipriano de Rivas Cherif, y dramaturgos como los hermanos Álvarez Quintero — por quienes Xirgu profesa "una devoción, honda, íntima [...], por una secreta corriente de simpatía, de pureza artística, de optimismo" (pág. 129)—Carlos Arniches, Jacinto Benavente, Alejandro Casona, Eduardo Marquina, Jacinto Grau, Lorca o 
Valle-Inclán. Entre noticias de estrenos, cotilleos de platea y disensiones con críticos, la actriz deja constancia del esplendor y las miserias de un oficio muy duro, gratificante unas veces y desesperante otras, así como de la difícil responsabilidad de compatibilizar arte y taquilla.

El tercer bloque de cartas abarca desde 1931 hasta 1939, esto es, desde la Segunda República hasta el fin de la Guerra Civil. La primera fechada en Madrid el 15 de abril de 1931 - es una emotiva y reveladora carta en que la actriz le expresa a su hermano su alegría por la proclamación de la República, que celebra paseando por la Puerta del Sol. Mucho más duras son las enviadas después del estallido de la guerra, que Xirgu sigue con consternación desde América Latina, donde sufre también las consecuencias morales y materiales de la contienda.

La correspondencia entre los años 1943 y 1949 consta solo de cuatro cartas — entre ellas, una a Max Aub y otra a Cipriano de Rivas Cherif-, que permiten reconstruir parte de su trayectoria vital y escénica durante el exilio. En su carta a Francisco Graña, Xirgu cuenta cómo fue procesada y condenada por el Tribunal de Responsabilidades Políticas a la confiscación total de sus bienes y a extrañamiento a perpetuidad. Aunque se define como "mujer de lucha artística y no de lucha política" (pág. 226), su compromiso es innegable, como lo es el dolor que siente por la tragedia de la guerra de España.

Entre 1950 y 1956, período que cubre el quinto bloque de la correspondencia, Xirgu se halla definitivamente instalada en Uruguay. Es un período muy fructífero donde enlaza compromisos y proyectos no solo como intérprete sino también como directora y pedagoga. Abundan las cartas a su amiga Alicia Rodríguez Romero, traductora de teatro y colaboradora en el Ministerio de Instrucción Pública de Uruguay, y a su marido, Ángel Curotto, que le ofrece a la actriz catalana excelentes condiciones laborales tanto en el ámbito de la escena como en el de la docencia —entre 1949 y 1957, Xirgu alternó la dirección de la Escuela Municipal de Arte Dramático con la codirección estable de la Comedia Nacional del Uruguay-. Por otra parte, se incrementa el volumen de cartas a su familia en Cataluña, sobre todo a su hermano Miquel — con quien intercambia impresiones sobre teatro y escenografía - y a su ahijada Margarita. A pesar de que el retorno a Cataluña es un asunto recurrente en sus cartas familiares, cada vez es más obvio su arraigo en América.

El sexto es el bloque más extenso — 103 cartas_- y abarca desde 
1957 hasta 1963. Muchas de estas cartas van dirigidas a su familia y recurren a menudo al tema del regreso y la añoranza; abundan asimismo en noticias y comentarios sobre actrices, autores, éxitos, contratos, a menudo con un lenguaje trufado de expresiones populares, no exentas de humor, y bastantes catalanismos. El séptimo y último período abarca desde 1964 hasta 1969, ya en Punta Ballena, su paraíso en los años de retiro.

Por respeto al criterio de autoría, se publican en anexo las cartas de Miguel Ortín, su segundo marido. De todas ellas, las más interesantes son las dieciséis dirigidas a José Ricardo Morales, exiliado en Santiago de Chile, y también las cuatro escritas a Domènec Guansé, que documentan la biografía sobre la actriz que este preparaba para la Editorial Alcides. Las que escribe tras la muerte de su esposa dan cuenta de cómo fueron los acontecimientos y homenajes póstumos que revelaban la admiración y el cariño que la actriz supo granjearse en América.

Como dice Francesc Foguet, el teatro es para Margarita Xirgu una sagrada obligación que le impone su vocación indomable. Las aportaciones de esta gran actriz y directora, la más reconocida de la escena española tras la muerte de María Guerrero, fueron valiosísimas: ampliación y modernización del repertorio, simplificación de la tramoya, eliminación de la figura del apuntador, trabajo actoral caracterizado por una gran naturalidad, viveza y profundidad psicológica. Rafael Alberti se declaró ferviente admirador suyo; Lorca la vio siempre en la encrucijada de las heroínas. Este magnífico epistolario, documento excepcional que nos permite conocer mejor su personalidad teatral y política, así como conferirle al mito una dimensión más humana, resulta una aportación de primera magnitud para la historia del teatro contemporáneo.

Ana Prieto Nadal SELITEN@T 